\title{
Comparison of rainfall generators with regionalisation for the estimation of rainfall erosivity at ungauged sites
}

\author{
Ross Pidoto ${ }^{1}$, Nejc Bezak ${ }^{2}$, Hannes Müller-Thomy ${ }^{3,4,+}$, Bora Shehu ${ }^{1}$, Ana Claudia Callau-Beyer ${ }^{5}$, \\ Katarina Zabret $^{2}$, Uwe Haberlandt ${ }^{1}$ \\ $5 \quad{ }^{1}$ Institute of Hydrology and Water Resources Management, Leibniz University Hannover, Germany \\ ${ }^{2}$ University of Ljubljana, Faculty of Civil and Geodetic Engineering, Ljubljana, Slovenia \\ ${ }^{3}$ Leichtweiß Institute for Hydraulic Engineering and Water Resources, Department of Hydrology, Water Management and \\ Water Protection, Technische Universität Braunschweig, Brunswick, Germany \\ ${ }^{4}$ Institute of Hydraulic Engineering and Water Resources Management, Vienna University of Technology, Austria \\ $10 \quad{ }^{5}$ Institute of Horticultural Production Systems, Leibniz University Hannover, Germany \\ +previously published under the name Hannes Müller
}

Correspondence to: Hannes Müller-Thomy (h.mueller-thomy@tu-braunschweig.de)

\begin{abstract}
The assessment of rainfall erosivity is one of the main inputs in determining soil erosion. To calculate mean annual rainfall erosivity (R), long-term high-resolution observed rainfall time series are required, which are often not available. To overcome the issue of limited data availability in space, four methods are employed: the direct regionalisation of R, the regionalisation of 5 minute rainfall, the disaggregation of daily rainfall into 5 minute timesteps, and the use of a regionalised stochastic rainfall model. In addition the minimum time series length necessary to adequately estimate $\mathrm{R}$ is investigated. The impact of station density is considered for each of the methods. The study is carried out using 159 recording and 150 nonrecording (daily) rainfall stations in the federal state of Lower Saxony, Germany. Results show that the direct regionalisation of mean annual erosivity leads to the best results in terms of relative bias and relative root mean square error (RMSE). This is followed by the regionalisation of the 5 minute rainfall data, which yields better results than the rainfall generation models, namely an alternating renewal model (ARM) and a multiplicative cascade model (Disagg). However, a key advantage of using regionalised rainfall models is the generation of rainfall time series that can be used for the estimation of the erosive event characteristics, which is not possible through the direct regionalisation of R. Using the stochastic ARM it can be shown that in most cases more than 60 years of data is needed in order to obtain a stable estimate of the annual rainfall erosivity. Estimation of soil erosion based on only 5 or 10 years of data can lead to uncertain values. Such short time series are often used when regionalisation is applied. Moreover, it was also found that resolution of measuring device has a significant effect on the rainfall erosivity and coarser data resolution can lead to high relative bias.
\end{abstract}




\section{Introduction}

Intense soil erosion has a significant impact on the environment, for example it can present a major threat for agricultural production or lead to increased sedimentation and pollution in rivers, which can also affect aquatic organisms. Soil erosion modelling can be applied in order to detect the most critical areas and design suitable measures for soil loss reduction. One of the most frequently applied models for the soil erosion modelling is the Universal Soil Loss Equation (USLE) and in its followup version named Revised Universal Soil Loss Equation (RUSLE) (e.g., Renard et al., 1997). In the scope of the RUSLE model, soil erosion is described with six factors, one of which is the rainfall erosivity factor R (in MJ mm ha-1 h-1, Renard et al., 1997). Rainfall erosivity is often characterised by large spatial and temporal variability (e.g., Bezak et al., 2020, 2021a, 2021b; 2021c; Panagos et al., 2016, 2017; Petek et al., 2018), which means that rainfall erosivity estimations are not a straightforward task and require adequate temporal and spatial data resolution.

In order to obtain robust rainfall erosivity values, high-resolution observed rainfall estimates are needed, ideally with a 1 or 5 minute resolution (Dunkerley, 2019). However, rainfall data at this resolution is often only available for shorter periods of observation (e.g. 10 or 20 years) or not at all. A solution to overcome this shortcoming is the use of stochastic rainfall models that allows the generation of long time series of arbitrary length. A few studies have investigated the possibility of applying stochastic precipitation models to generate rainfall time series that can be used to estimate rainfall erosivity (e.g., Jebari et al., 2012; Lobo et al., 2015; de Oliveira et al., 2018; Haas et al., 2018). Different methods have been developed for the generation of rainfall itself such as cluster-based models (e.g., Onof et al., 2000, Onof and Wang, 2020), cascade models (e.g., Molnar and Burlando, 2005; Müller and Haberlandt, 2018), method-of-fragments (e.g., Breinl and Di Baldassarre, 2019) or alternating renewal models (e.g., Callau Poduje and Haberlandt, 2017), or as part of weather generators (Peleg et al., 2016). The parameters of these methods are estimated based on observations and the complexity of the models depends on the selected time step of data. Thus, most studies are focused on daily data. For example, CLImate GENerator (CLIGEN) was applied to obtain daily rainfall estimates and calculate rainfall erosivity using daily data (e.g., de Oliveira et al., 2018; Lobo et al., 2015; Wang et al., 2018). However, some shortcomings such as sensitivity to the selection of input parameters of the above mentioned models have been reported in the literature (e.g., Meyer et al., 2008; Haas et al., 2018). On the other hand, temporal high-resolution time series (i.e. 5 minutes) are not frequently generated using stochastic rainfall models, although, in recent years advancements have been made in terms of high frequency rainfall data simulations (e.g., Haberlandt et al., 2008; Vandenberghe et al., 2011; Vernieuwe et al., 2015, Callau Poduje and Haberlandt, 2017, Müller-Thomy, 2020).

Thus, a few studies (e.g., De Oliveira et al., 2018; Haas et al., 2018) have investigated if stochastic rainfall models are able to correctly predict the rainfall erosivity pattern at specific locations. In the case that a stochastic rainfall model is able to mimic the rainfall erosivity characteristics, generated long-term high-resolution rainfall time series should allow a robust estimation of annual and monthly erosivity pattern. Similarly, a limited number of studies (e.g., Angulo-Martinez et al., 2009) have investigated the issue of observed high-resolution data in space. 
Therefore, the main aim of this study is to evaluate and compare different rainfall generators and regionalisation approaches in order to obtain either directly or indirectly rainfall erosivity estimates for ungauged locations. Given a lack of high-resolution rainfall time series, the research question is whether these methods can adequately reproduce observed rainfall erosivity statistics. In addition, one further research question is posed. Given the existence of a high-resolution rainfall time series, how long should this time series be in order to obtain stable site rainfall erosivity statistics?

All tests are performed via leave-one-out cross validation, as the premise of this study is that high-resolution time series are not widely available. Additionally, the effect of station density on the regionalisation performance is assessed by performing each test at five different station counts. To minimise the sampling uncertainty, 20 realisations of each test at each station density are performed.

\section{Data and study area}

High-resolution observed rainfall data for 159 stations in and around the northern German federal state of Lower Saxony (Fig.

75 1) was acquired from the German Weather Service (DWD). The one minute source time series, from a combination of tipping bucket and later drop counter measurements, were aggregated to 5 minutes for use within this project. All data used for the project is restricted to the ten year period 2007-2016, as all 159 stations have at least $98 \%$ data availability for this period. The study area is dominated by lowland terrain, with the only mountains of significance being the south east lying Harz mountain range. The region is predominantly classified as having a temperate oceanic $(\mathrm{Cfb})$ climate according to Köppen-Geiger (Kottek

80 et al., 2006). The far eastern portion of the study area is categorised as temperate continental (Dfb) and the Harz mountain range as cool continental (Dfc). Fig. 2 displays the long-term seasonal rainfall and temperature variability averaged over the German federal state of Lower Saxony. Annual rainfall varies between $950 \mathrm{~mm}$ in the Harz mountain range to under $400 \mathrm{~mm}$ in lower lying areas east of the study area.

\section{Methods}

85 In this study, four different methods to calculate annual rainfall erosivity (R) for ungauged sites are applied (Fig. 3). The first and simplest is the direct regionalisation of observed mean annual rainfall erosivity (method Direct-R). The other three methods all generate rainfall time series first from which mean annual rainfall erosivity is subsequently calculated. The second is the regionalisation of the observed 5 minute rainfall time series (method Direct-P). The final two methods are stochastic rainfall models - one being a regionalised disaggregation model using regionalised daily rainfall as its source (method Disagg) (Müller-

90 Thomy, 2020) and the other a regionalised alternating renewal model (method ARM) (Callau Poduje and Haberlandt, 2017). Detailed descriptions of the applied methods are provided in sections 3.2 and 3.3 while section 3.1 provides details about the rainfall erosivity calculation. 


\subsection{Rainfall erosivity}

Rainfall erosivity is one of the factors that has the highest impact on soil erosion rates. Rainfall erosivity is characterised by multiple properties of rainfall events such as the kinetic energy of raindrops, rainfall intensity and rainfall duration. In order to calculate annual rainfall erosivity for a selected time span of $M$ years, the following equation proposed by Renard et al. (1997) can be used:

$R=\frac{\sum_{n} E \cdot I_{30}}{M}$

where $R$ is rainfall erosivity $\left(\mathrm{MJ} \mathrm{mm} \mathrm{ha-1} \mathrm{h}^{-1}\right), I_{30}$ is the maximum 30 minute rainfall intensity for a specific rainfall event (mm $\left.\mathrm{h}^{-1}\right), E$ is the kinetic energy of the rainfall event $\left(\mathrm{MJ} \mathrm{ha}^{-1}\right)$ and $n$ is the total number of erosive events. Equation 2 is used to derive the kinetic energy of the rainfall event:

$E=e_{B} \cdot I \cdot \Delta t$

where $e_{B}$ is specific kinetic energy $\left(\mathrm{MJ} \mathrm{ha}^{-1} \mathrm{~mm}^{-1}\right), I$ is rainfall intensity $\left(\mathrm{mm} \mathrm{h}^{-1}\right)$ for the event and $\Delta t$ is the time interval. Various equations for calculation of $e_{B}$ were developed for different parts of the world, where most often high frequency measurements using optical disdrometers are used in order to derive the $e_{B}-E$ relationship (e.g., Petan et al., 2010). One of the most frequently and globally used equations (e.g., Panagos et al., 2015, 2017) was proposed by Brown and Foster (1987):

$$
e_{B}=0,29 \cdot[1-0,72 \cdot \exp (-0,05 \cdot I)]
$$

This equation is also mentioned in the RUSLE Handbook (Renard et al., 1997), which means that it should be regarded as a standard method when one wants to estimate the soil erosion using the RUSLE method. Additionally, the equation has been already applied several times to similar climatic conditions (e.g., Panagos et al., 2015) and yielding meaningful results. This equation was also used in the presented study in order to calculate specific kinetic energy. The equation 3 is valid for the rainfall intensity in the range between 0 and $250 \mathrm{~mm} / \mathrm{h}$.

Erosive rainfall events are defined according to the RUSLE methodology (Renard et al., 1997). A rainfall event is considered erosive if the total volume exceeds $12.7 \mathrm{~mm}$ of rain or if the maximum volume in 15 minutes is more than $6.35 \mathrm{~mm}$. Here a 6

115 hour period without rain is used in order to separate two consecutive erosive rainfall events. The monthly and annual rainfall erosivity values are then calculated based on the rainfall erosivity of all erosive events.

\subsection{Direct regionalisation methods}

\subsubsection{Method Direct-R: direct regionalisation of mean annual rainfall erosivity $R$}

The direct interpolation of erosivity is carried out using geostatistical methods (see e.g. textbooks from Isaaks and Srivastava, 
where $c$ is $0.5, c_{0}$ is 0.3 and aeff is $30000 \mathrm{~km}$. For interpolation ordinary kriging (OK) and external drift kriging (EDK) are applied. While OK assumes spatial stationarity, EDK relaxes the intrinsic hypothesis regarding the constant mean and assumes a linear relationship between the mean of the target variable $\mathrm{Z}$ and one or more additional variables $\mathrm{Y}$ :

The coefficients a and $b_{i}$ need not be known explicitly, but are considered in building the kriging system. The additional variables $Y_{i}$ need to be provided for all points with observed erosivity and for all unobserved points to be interpolated, usually on a raster. Here, the following additional variables are used in the analyses: daily mean rainfall (Pmean), maximum daily rainfall (Pmax), the 90 and 99 percent quantiles of daily rainfall $(P q 90, P q 99)$ and the yearly wet fractions of days with rainfall higher than $12.7 \mathrm{~mm}$ (based on the RUSLE methodology; Renard et al., 1997) and $1 \mathrm{~mm}$ thresholds (wfd12, wfdl). These variables are extracted from regionalised daily data in a spatial resolution of $1 \mathrm{~km}^{2}$ (NLWKN, 2019), and are calculated as long-term averages from the period 2007-2016. The interpolation uses a minimum of 8 neighbours and a maximum of 12 neighbours within a radius of $300 \mathrm{~km}$. The R statistical software with the package "gstat" (Pebesma, 2004) is employed for the calculations.

\section{3.2.2 Method Direct-P: regionalisation of 5 minute rainfall}

A second approach for the regionalisation of the annual $\mathrm{R}$, is to estimate the 5 minute rainfall time series for unobserved locations based on the information of nearby measured rainfall time series. In this study, the nearest neighbor approach (NN) is used for the regionalisation of the 5 minute rainfall time series from 2007-2016. This technique, also known as the Thiessen Polygon method (Thiessen, 1911), is a simple approach which assigns for each unobserved point the observed rainfall time series of the closest available rain gauge. Despite this being a basic interpolation method, a prior investigation of different interpolation techniques (nearest neighbor, inverse distance and ordinary kriging) led to the conclusion that this technique maintains the best temporal structure of rainfall at the 5 minute time scale and yields the lowest error for the calculation of erosivity. One reason for the superiority of $\mathrm{NN}$ compared to the other interpolation methods might be that $\mathrm{NN}$ is the only method which is not smoothing the extremes, which is important here for the estimation of erosive events.

\subsection{Stochastic rainfall models}

\subsubsection{Method ARM: an alternating renewal rainfall model}

The stochastic alternating renewal model (ARM) is based on the theory of renewal processes. Rainfall is described as a series of independent alternating wet and dry spells, described by the three variables: wet spell amount (WSA), wet spell duration (WSD) and dry spell duration (DSD) (Fig. 4).

150 Probability distributions are fitted to observations of these variables, with observed rainfall events being limited by a minimum WSA $(1 \mathrm{~mm})$ and DSD (60 min). Synthetic rainfall time series of arbitrary length can be generated by producing random variates of the distributions. 
Additionally, the temporal distribution of rainfall within a wet spell is described by a double exponential function conditioned on the wet spell time to peak (WSTP - modelled using a uniform distribution) and wet spell peak intensity (WSPI - modelled using a copula, see below), and WSA (Fig. 5). Full details of the model can be found in Callau and Haberlandt (2017), with the following alterations which have been found to provide a better model performance, especially when considering regionalisation:

- $\quad$ an Khoudraji Gumbel copula describes the dependence between WSA and WSD

- a Tawn copula describes the dependence between WSD and the ratio WSPI:WSA

- the three parameter Weibull distribution is used instead of the four parameter Kappa distribution for the variables DSD and WSA, being more robust in a regionalisation setting.

\subsubsection{Method Disagg: cascade model}

Another possibility to generate high-resolution rainfall time series is to disaggregate daily time series, which exist most often for longer time periods and with higher station densities. For this study the micro-canonical cascade model after Müller-Thomy

165 (2019, 2020) is applied due to its performance in previous studies (e.g. Müller and Haberlandt, 2015, 2018). The general cascade model scheme with disaggregating one coarse time step into "b" finer time steps is illustrated in Fig. 6. From daily rainfall amounts three time steps with $8 \mathrm{~h}$ duration are generated $(b=3)$. For all further disaggregation steps $b=2$ is applied, resulting in temporal resolutions of $\Delta \mathrm{t}=\{4 \mathrm{~h}, 2 \mathrm{~h}, 1 \mathrm{~h}, 30 \mathrm{~min}, 15 \mathrm{~min}, 7.5 \mathrm{~min}\}$. To achieve $\Delta \mathrm{t}=5 \mathrm{~min}$, a linear transformation is applied. The rainfall amount is conserved exactly in each disaggregation step. For a detailed description of the cascade model the reader is referred to the description of the preceding cascade model in Müller-Thomy (2020).

The cascade model parameters are estimated by the aggregation of observed 5 min time series of the recording stations available in each density scenario. As daily time series the aggregated 5 min time series of all 159 stations are used, independent of the applied density scenario. To investigate how suitable is the disaggregation of daily information for unobserved locations, a regionalisation of the daily precipitation is done prior to the application of the cascade model. Here ordinary kriging approach (OK) was used for the regionalisation of daily rainfall time series from 2007-2016. The interpolation uses an isotropic exponential variogram as in Eqn. 6, a minimum of 4 neighbours and a maximum of 12 neighbours within a radius of $150 \mathrm{~km}$.

$\gamma(h)=c_{0}+c\left[1-\exp \left(-\frac{h}{a}\right)\right]$

where $c_{0}$ is $0.4, c$ is 1.5 and aeff is $186280 \mathrm{~km}$.

\subsection{Regionalisation schemes and station selection}

180 In order to adequately test the performance of the different methods, all regionalisations have been performed in a cross validation mode at varying station densities. Five station densities were chosen $-20 \%(\mathrm{~N}=32), 40 \%(\mathrm{~N}=64), 60 \%(\mathrm{~N}=96)$, $80 \%(\mathrm{~N}=128)$ and $100 \%(\mathrm{~N}=159)$ of the total available station count. Stations were selected at random and are consistent across the different testing methods presented above. Important to note is that the cross validation is only performed on the stations chosen at the $20 \%$ level $(\mathrm{N}=32)$ - the higher densities only add further supplementary stations available for the 
regionalisation, with the assumption that the regionalisation performance will improve at a higher available station count. Furthermore, 20 realisations are performed for each density to minimise the influence of station selection on the results. This scheme is illustrated graphically in Fig. 7.

\subsection{Effect of time series length on the calculation or mean annual $R$}

One further research question of interest is how long a rainfall time series must be in order to achieve a stable (i.e. robust) result of mean annual rainfall erosivity. The importance of such a research question lies in the fact that rainfall series used to calculate annual erosivity are often of limited length. Therefore, using only a few years of data could perhaps lead to uncertain estimations of rainfall erosivity, which could affect the estimated soil erosion (i.e. under- or overestimation).

Using the alternating renewal rainfall model described in section 3.3.1, it is investigated how many years of data are needed in order to obtain stable estimations of the annual rainfall erosivity. For this purpose, 18 stations with the longest observation time series length are selected to achieve better model fitting. For each station the ARM model described in section 3.3.1 is fitted. Afterwards, 200 years of synthetic rainfall time series are generated 50 times for all 18 stations. The effect of time series length is investigated by calculating mean annual rainfall erosivity for each station and for each realisation using separately 2 , $5,10,20,30,40,50,60,70,80,90,100,120,140,160,180$ and 200 years of data. Results within $\pm 20 \%$ of the mean annual erosivity calculated for 200 years are considered stable.

\subsection{Evaluation criteria}

To assess the relative performance of the four different methods (Fig. 3), three different evaluation criteria are chosen. The first is the Pearson correlation coefficient $r_{x y}$ between the annual rainfall erosivity calculated from observed rainfall and the estimated mean annual erosivity, i.e. regionalised by the different methods, at a given station density scenario across all realisations and the 32 reference stations. It is worth remembering that this measure is an indication of linear correlation only.

205 It is given by the formula:

$\mathrm{r}_{\mathrm{xy}}=\operatorname{cov}(x, y) / \sigma(x) * \sigma(y)$

where cov is the covariance and $\sigma(x)$ and $\sigma(y)$ are the standard deviations of $x$ and $y$ (rainfall erosivity calculate from observed and simulated data), respectively. The second is the relative root mean square error (RMSE) of the mean annual rainfall erosivity for a given station density scenario across all realisations and stations, given by equation 8 :

$R M S E=\sqrt{\frac{1}{N} \sum_{n=1}^{N}\left[\frac{y-x}{x}\right]^{2}}$

where $x$ refers to mean annual rainfall erosivity estimated from observations, $y$ is the estimated mean annual rainfall erosivity estimated by the different methods proposed in this work and $N$ is the number of stations. The third is the median relative bias $r B_{\text {med }}$ of the mean annual erosivity. For a given station density scenario the relative bias $r B$ is calculated over all 32 stations for one realisation, and the median relative Bias $r B_{\text {med }}$ is provided as summarizing result (referred to as relative Bias in the 215 following): 
Additionally, a comparison using absolute rainfall erosivity values is also provided.

\section{Results and discussion}

\subsection{Mean annual erosivity $R$}

220 The main focus of this study is to evaluate the performance of the four different tested methods in reproducing observed mean annual erosivity. For the direct regionalisation of erosivity (Direct-R), EDK with mean annual precipitation $\left(\mathrm{P}_{\text {mean }}\right)$ as external drift was found to provide the best performance. The direct regionalisation provides the best results overall, both in terms of accuracy and precision. The Pearson correlation (Fig. 8) by this method is larger than for the other three methods, which show more or less the same result. Its root mean square error is also lower than the other methods (Fig. 8). The rBmed is the only performance criteria where this method is not clearly better (Fig. 8). In terms of rBmed the Direct-R method is followed by Direct-P. ARM and Disagg in most cases yield relative bias larger than 10 and 20\%, respectively. In terms of relative RMSE and Pearson Correlation the ARM and Disagg methods perform relatively similarly. The median result over all realisations shows slightly better results for the direct regionalisation of rainfall (Direct-P) compared to stochastic rainfall models, although the range of results is greater than for Direct-R. The disaggregation model performs worse than the other methods with a $>20 \%$ underestimation of mean annual erosivity. With increasing station density, the median result is generally improved, in particular for the Pearson correlation (Fig. 8). This is less noticeable for rBmed, as bias likely indicates the inherent ability of the underlying method to replicate the mean annual R (Fig. 8). Moreover, it seems that for ARM and Direct-P the results change greatly between realisations (i.e. larger spread of the results), meaning that the station setting is more decisive, with Direct-P being the most affected. The Direct-R and Disagg methods seem to be more robust in terms of station setting, which indicates their usage for regions with low station densities. Thus, it seems that for areas similar to that of Lower Saxony (i.e. relatively flat areas with small changes in erosivity), the Direct- $\mathrm{R}$ method is preferred in case that one needs to estimate the rainfall erosivity for the ungauged locations. The application of this method is also the simplest of the four methods (Fig. 3), especially when compared to the ARM and Disagg methods, since these two methods require development of the stochastic rainfall models and estimation of the model parameters. Thus, in terms of mean annual rainfall erosivity, the use of stochastic rainfall models does not provide an improvement of the results in terms of performance in space (Fig. 8). In terms of the number of stations needed to provide good estimates of rainfall erosivity for the ungauged locations, it is clear that higher station counts available for the regionalisation yield better results, which could be expected (Fig. 8). Thus, for the Direct-R the performance D100>D80>D60>D40>D20 (Fig. 8) with somewhat diminishing improvements in performance above D80. Similar conclusions can be made for the Direct-P method while for the ARM and Disagg this relationship is not so evident for the rBmed and RMSE (Fig. 8). Therefore, even for topographically relatively homogeneous areas (compared to for example 
https://doi.org/10.5194/esurf-2022-1

Alpine area) such as Lower Saxony, the accuracy of rainfall erosivity maps greatly depends on the number of stations used for the interpolation.

\subsection{Erosive event characteristics}

Although the main focus of the study is the calculation of the mean annual erosivity $\mathrm{R}$, in some specific applications more details about the rainfall erosivity at a location might be required. For example, studies that investigate changes in erosivity patterns in time (i.e. climate change studies) might be interested in changes in the number of erosive events or erosive events characteristics. In such a case the Direct-R method cannot be used since this method is only able to provide estimates of the mean annual rainfall erosivity and does not provide a time series of erosive events. Naturally a similar procedure as in the case for Direct-R (section 3.2.1) could be used for any other variable of interest (e.g. number of erosive events, mean duration of the erosive events). However, the EDK setup used for mean annual $\mathrm{R}$ is unlikely to be optimal for other variables, which means that an optimal EDK setup would need to be investigated for each variable of interest separately and thus could be considered as relatively time consuming.

However, three of the four methods presented in this study, namely Direct-P, ARM and Disagg, are able to reproduce erosive events themselves from which the mean annual $\mathrm{R}$ is calculated. How well the three methods reproduce erosive event characteristics is explored in this section. Fig. 9 displays the median relative bias of different erosive event variables. The mean annual event count and precipitation sum (first two box plots) is best represented by the Direct-P method. Whereas the median error is close to zero, the range of errors is well over $100 \%$ when one considers outliers. The Disagg method represents the event count well but underestimates the annual volume slightly, whereas the ARM method underestimates both the annual count and volume (Fig. 9). Performance improves slightly for all methods with increasing station density (not shown).

265 For both the mean event duration and volume (Fig. 9, last two box plots), the results again show that the Direct-P method is the most efficient. The Disagg method significantly overestimates the event duration and at the same time underestimates the event volume. However, its overall performance is achieved already for the low density scenarios (not shown here). An overestimation of the erosive events duration is to be expected as previously identified by Jebari et al. (2012) with underestimations higher than $40 \%$. Here the overestimations are higher as the disaggregation inherits the errors caused by the regionalization of the daily rainfall. Because of the unbiased estimator, OK tends to smoothen the spatial structures of the rainfall, leading to overestimation of the low intensities (explaining the longer event durations) and underestimation of the extreme ones (explaining the lower event volumes). The performance of the disaggregation may improve if another regionalization method that captures better the temporal variability is employed.

The ARM method underestimates both mean event duration and mean event volume, which explains the underestimation in both annual number of events and their volume. Thus, it can be seen that Direct-P outperforms the ARM and Disagg methods not only in terms of annual rainfall erosivity but also in terms of specific events characteristics. In case that one would like to obtain characteristics of the erosive events for the ungauged sites the Direct-P method should be preferred since it is able to produce acceptable results and yields better performance compared with the two tested stochastic rainfall models. 


\subsection{Annual rainfall erosivity - data length sensitivity}

Despite the fact that Direct-R and Direct-P methods yield better performance than the evaluated stochastic rainfall models, the benefit of the latter is the ability to generate long time series of arbitrary length of high-resolution data for (almost) unobserved areas, where Direct-R and Direct-P are not applicable at all. The goal of this section is to investigate how long the synthetic time series should be in order to obtain a stable estimate of the mean annual rainfall erosivity, which is most frequently used as an input to the soil erosion models (Panagos et al., 2015; 2017). Using the ARM model and the methodology described in section 3.5 it is investigated how many years of data is needed in order to obtain stable annual rainfall erosivity estimation. Important to remember is that the ARM model performance is better than what was shown in sections 4.1 and 4.2 as the ARM model in this section is fitted directly to observations and not regionalised. Fig. 10 shows results of this investigation. It can be seen that the variability between different realizations is quite high (Fig. 10). Moreover, investigation of the intersection between the 5 and $95 \%$ quantile values and $+-20 \%$ variation of the mean annual rainfall erosivity indicates that in case of 5\% quantile in most cases 60 years of data are needed in order to obtain a value that is between the +-20\% interval (Fig. 10). This indicates that calculations of the annual rainfall erosivity for the soil erosion modelling using USLE or RUSLE (e.g., Renard et al., 1997; Panagos et al., 2017) using only a limited sample size (e.g., less than 5 or 10 years) will likely result in a greater than $+-20 \%$ difference to the long term mean. Consequently, a similar impact (i.e. over- or under-estimation) on the calculated soil erosion rates will be obtained if one applies the RUSLE equation for the prediction.

\section{Conclusions}

This study evaluates four methods that can be used to estimate the annual mean erosivity $(\mathrm{R})$ in space. Based on the presented results the following conclusions can be drawn:

1. Both tested direct regionalisation methods (Direct-R and Direct-P) outperform the tested stochastic rainfall models (ARM and Disagg), with slightly better results for Direct-R. Furthermore, in terms of method complexity, this can be regarded as the simplest since it does not require the fitting of any model parameters. Differences among tested methods are relatively large, for example, in relative bias up to $25 \%$.

The main drawback of the Direct-R method is that it cannot be used to estimate the number of erosive events or mean event duration without applying the model to every variable separately (e.g., number of erosive events, annual rainfall erosivity). Therefore, the Direct-P method has the advantage that it is able to generate high-resolution time series of erosive events for ungauged sites. Therefore, information about the number of erosive events and the characteristics of erosive events can be determined as well.

2. In terms of the characteristics of the erosive events, the Direct-P method yields better performance than both tested stochastic rainfall models.

3. Both rainfall generators have proven their applicability in the field of soil erosion modelling since they are able to produce long synthetic series of the high-resolution data.

4. Cross validation methodology using multiple density scenarios (Fig. 7) has indicated that performance of all methods slightly increases with increasing station density. 
Investigation of the impact of time series length on the annual rainfall erosivity for 18 stations is carried out using the ARM model:

5. More than 60 years of data is required in the case that one would like to obtain rainfall erosivity estimates within $20 \%$ of the actual long-term mean annual rainfall erosivity.

Thus, this conclusion is of critical importance for soil erosion studies where rainfall erosivity estimates are used as input, since in most cases the high-resolution data used to estimate rainfall erosivity is much shorter than 60 years. So in cases where only 5-10 years of observed rainfall data is available, the estimated mean annual rainfall erosivity can be up to $\pm 100 \%$ in comparison to the actual long-term mean annual rainfall erosivity, which can be reduced by the application of one of the here used rainfall generators.

It should be noted that the approaches presented in this paper should be applied and tested for further case studies with different rainfall and topographical characteristics than for Lower Saxony, which is mostly flat and without major orographic obstacles. Additionally, some study limitations and lessons learned can also be made based on the presented results and conclusions such as that resolution of the measurement device, which has evolved in the recent decades, has a significant effect on the calculated rainfall erosivity and relative bias (Supplement; Fig. S1).

\section{Funding}

The results of the study are part of the bilateral research project between Slovenia and Germany "Stochastic rainfall models for rainfall erosivity evaluation" and research Programme P2-0180: "Water Science and Technology, and Geotechnical 330 Engineering: Tools and Methods for Process Analyses and Simulations, and Development of Technologies" (P2-0180) that is financed by the Slovenian Research Agency (ARRS). We acknowledge support by the Open Access Publication Funds of Technische Universität Braunschweig. Hannes Müller-Thomy has been financially supported by the DFG e.V., Bonn, Germany, as a Research Fellowship (MU 4257/1-1). Additionally, part of the results were also obtained in the scope of the bilateral project between Slovenia and Germany "Validation of precipitation reanalysis products for rainfall-runoff modelling in Slovenia (PRE-PROMISE)".

\section{Acknowledgment}

We would like to acknowledge the German Weather Service (DWD) for providing the data used in this study.

\section{Competing Interest}

Authors declare no conflict of interest. 
https://doi.org/10.5194/esurf-2022-1

Preprint. Discussion started: 1 February 2022

(c) Author(s) 2022. CC BY 4.0 License.

(c) (i)

\section{Author contribution}

All authors developed the concepts of the manuscript. R.P. conducted most of the calculations with support of the B.S., H.M.T., U.H., N.B. N.B. drafted the first version of the manuscript, all authors contributed to writing and editing of the manuscript.

\section{Code and data availability}

Data can be requested from the German Weather Service (DWD), the codes used in this study are freely available upon request from the first author.

\section{References}

Angulo-Martínez, M., López-Vicente, M., Vicente-Serrano, S. M., and Beguería, S. Mapping rainfall erosivity at a regional scale: a comparison of interpolation methods in the Ebro Basin (NE Spain), Hydrology and Earth System Sciences, 13, 19071920, https://doi.org/10.5194/hess-13-1907-2009, 2009.

350 Bezak, N., Ballabio, C., Mikoš, M., Petan, S., Borreli, P. and Panagos, P. Reconstruction of past rainfall erosivity and trend detection based on the REDES database and reanalysis rainfall, Journal of Hydrology, 590, 125372, doi: 10.1016/j.jhydrol.2020.125372, 2020.

Bezak, N., Borrelli, P., Panagos, P. A first assessment of rainfall erosivity synchrony scale at pan-European scale, Catena, 198, 105060, doi: 10.1016/j.catena.2020.105060, 2021a.

355 Bezak, N., Mikoš, M., Borrelli, P., Liakos, L., Panagos, P. An in-depth statistical analysis of the rainstorms erosivity in Europe, Catena, 206, 105577, doi: 10.1016/j.catena.2021.105577, 2021b.

Bezak, N., Petan, S., Mikoš, M. Spatial and temporal variability in rainfall erosivity under Alpine climate: a Slovenian case study using optical disdrometer data, Frontiers in Environmental Science, 423, doi: 10.3389/fenvs.2021.735492, 2021c.

Breinl, K. and Di Baldassarre, G. Space-time disaggregation of precipitation and temperature across different climates and 360 spatial scales. Journal of Hydrology: Regional Studies 21, 126-146, 2019.

Brown, L.C. and Foster, G.R. Storm Erosivity Using Idealized Intensity Distributions. Am. Soc. Agric. Biol. Eng. doi:10.13031/2013.31957, 1987.

Callau Poduje, A.C. and Haberlandt, U. Short time step continuous rainfall modeling and simulation of extreme events. Journal of Hydrology 552, 182-197, 2017.

365 CDC. 2020. Climate Data Center, available at: https://www.dwd.de/EN/climate environment/cdc/cdc node.html (accessed: 15th of December 2020).

De Oliveira, J.P.B., Cecilio, R.A., Pruski, F.F., Zanetti, S.S. and Moreira, M.C. Assessing the use of rainfall synthetic series to estimate rainfall erosivity in Brazil. Catena 171, 327-336, 2018. 
https://doi.org/10.5194/esurf-2022-1

Preprint. Discussion started: 1 February 2022

(c) Author(s) 2022. CC BY 4.0 License.

Dunkerley, D. L. Rainfall intensity bursts and the erosion of soils: an analysis highlighting the needs for high temporal resolution rainfall data for research under current and future climates. Earth Surface Dynamics 7, 345-360, 2019.

DWD, CDC. 2020. German Weather Service (DWD) Climate Data Center. Available at: https://www.dwd.de/EN/climate environment/cdc/cdc_node.html.

Fagerland, M.W. and Sandvik, L. The Wilcoxon-Mann-Whitney test under scrutiny. Statistics in Medicine, 28: 1487-1497. doi: 10.1002/sim.3561, 2009.

375 Goovaerts, P. Geostatistics for Natural Resources Evaluation. Oxford University Press, 483 p., 1997.

Haas, J., Schack-Kirchner, H. and Lang, F. Adjustment of a weather generator to represent actual rain erosivity in the northern Black Forest - Germany. Catena 163, 42-53, 2018.

Haberlandt, U., Ebner von Eschenbach, A.D. and Buchwald, I. A space-time hybrid hourly rainfall model for derived flood frequency analysis. Hydrology and Earth System Sciences 12, 1353-1367, 2008.

380 Isaaks, E.H. and Srivastava, R.M. An Introduction to Applied Geostatistics. Oxford University Press, 592 p., 1990.

Jebari, S., Berndtsson, R., Olsson, J. and Bahri, A. Soil erosion estimation based on rainfall disaggregation. Journal of Hydrology 436-437, 102-110, 2012.

Kottek, M., Grieser, J., Beck, C., Rudolf, B. and Rubel, F. World Map of the Köppen-Geiger climate classification updated. Meteorologische Zeitschrift 15(3), 259-263. Doi: 10.1127/0941-2948/2006/0130, 2006.

385 Lobo, G.P., Frankenberger, J.R., Flanagan, D.C. and Bonilla, C.A. Evaluation and improvement of the CLIGEN model for storm and rainfall erosivity generation in Central Chile. Catena 127, 206-213, 2015.

Meyer, C.R., Renschler, C.S. and Vining, R.C. Implementing quality control on a random number stream toimprove a stochastic weather generator. Hydrological Processes 22(8), 1069-1079, 2008.

Molnar, P. and Burlando, P. Preservation of rainfall properties in stochastic disaggregation by a simple random cascade model.

390 Atmospheric Research 77, 137-151, 2005.

Müller, H. and Haberlandt, U. Temporal rainfall disaggregation using a multiplicative cascade model for spatial application in urban hydrology, in: Molnar, P., Peleg, N. (editors): Rainfall in urban and natural Systems, Proceedings of the 10th International Workshop on Precipitation in Urban Areas (UrbanRain15), Pontresina, 1-5 December 2015 (Paper UR15-43), ETH-Zürich, Institute of Environmental Engineering, doi:10.3929/ethz-a-010549004, 2015.

395 Müller, H. and Haberlandt, U. Temporal rainfall disaggregation using a multiplicative cascade model for spatial application in urban hydrology. Journal of Hydrology 556(2018), 847-864. doi: 10.1016/j.jhydrol.2016.01.031, 2018.

Müller-Thomy, H. Improving the autocorrelation in disaggregated time series for urban hydrological applications, P, In: Peleg, N., Molnar, P. (eds.), 11th Workshop on Precipitation in Urban Areas (UrbanRain18), Pontresina, Switzerland, pp. 75-76, 2019.

400 Müller-Thomy, H. Temporal rainfall disaggregation: Possibilities to improve the autocorrelation, Hydrology and Earth System Sciences, 24, 169-188, 2020. 
https://doi.org/10.5194/esurf-2022-1

Preprint. Discussion started: 1 February 2022

(c) Author(s) 2022. CC BY 4.0 License.

NLWKN. Globaler Klimawandel - Wasserwirtschaftliche Folgen für das Binnenland (KliBiW), Abschlussbericht Phase V. Niedersächsischer Landesbetrieb für Wasserwirtschaft, Küsten- und Naturschutz. Norden, 2019.

Onof, C., Chandler, R.E., Kakou, A., Northrop, P., Wheater, H.S. and Isham, V. Rainfall modelling using poisson-cluster

processes: A review of developments. Stochastic Environmental Research and Risk Assessment 14(6), 384-411, 2000.

Onof, C. and Wang, L.-P. Modelling rainfall with a Bartlett-Lewis process: New developments, Hydrology and Earth System Sciences 24, 2791-2815, 2020.

Panagos, P., Ballabio, C., Borrelli, P., Meusburger, K., Klik, A., Rousseva, S., Tadić, M.P., Michaelides, S., Hrabalíková, M.,

Olsen, P., Aalto, J., Lakatos, M., Rymszewicz, A., Dumitrescu, A., Beguería, S. and Alewell, C. Rainfall erosivity in Europe.

410 Sci. Total Environ. 511, 801-814. doi:10.1016/j.scitotenv.2015.01.008, 2015.

Panagos, P., Ballabio, C., Borrelli, P. and Meusburger, K. Spatio-temporal analysis of rainfall erosivity and erovity density in Greece. Catena 137, 161-172, 2016.

Panagos, P., Borrelli, P., Meusburger, K., Yu, B., Klik, A., Lim, K.J., Yang, J.E., Ni, J., Miao, C., Chattopadhyay, N., Hamidreza Sadeghi, S., Hazbavi, Z., Zabihi, M., Larionov, G.A., Krasnov, S.F., Gorobets, A.V., Levi, Y., Erpul, G., Birkel,

415 C., Hoyos, N., Naipal, V., Oliveira, P.T.S., Bonilla, C.A., Meddi, M., Nel, W., Al Dashti, H., Boni, M., Diodato, N., Van Oost, K., Nearing, M. and Ballabio, C. Global rainfall erosivity assessment based on high-temporal resolution rainfall records. Nat. Sci. Rep. 7. doi: 10.1038/s41598-017-04282-8, 2017.

Pebesma, E.J. Multivariable geostatistics in S: the gstat package. Computers \& Geosciences 30, 683-691, 2004.

Peleg, N., Fatichi, S. Paschalis, A., Molnar, P. and Burlando, P. An advanced stochastic weather generator for simulating 2-D high-resolution climate variables. Journal of Advances in Modeling Earth Systems 9, 1595-1627, 2016.

Petan, S., Rusjan, S., Vidmar, A. and Mikoš, M.. The rainfall kinetic energy-intensity relationship for rainfall erosivity estimation in the Mediterranean part of Slovenia. J. Hydrol., 391(3-4): 314-321, 2010.

Petek, M., Mikoš, M. and Bezak, N. Rainfall erosivity in Slovenia: Sensitivity estimation and trend detection. Environmental Research 167, 528-535, 2018.

425 R Core Team. R: A language and environment for statistical computing. R Foundation for Statistical Computing, Vienna, Austria. http://www.R-project.org/ (4. 10. 2017), 2015.

Renard, K.G., Foster, G.R., Weesies, G.A., McCool, D.K. and Yoder, D.C. Predicting soil erosion by water: a guide to conservation planning with the Revised Universal Soil Loss Equation (RUSLE), Agricultural Handbook No. 703. USDA ARS, Washington DC. doi:DC0-16-048938-5 65-100, 1997.

430 Vandenberghe, S., Verhoest, N.E.C., Onof, C. and De Baets, B. A comparative copula-based bivariate frequency analysis of observed and simulated storm events: a case study on Bartlett-Lewis modeled rainfall. Water Resourses Research 47(7), doi: 10.1029/2009WR008388, 2011.

Thiessen, A.H. Precipitation averages for large areas. Monthly Weather Review. 39.7, pp. 1082-1809, 1911.

Vernieuwe, H., Vandenberghe, S., De Baets, D. and Verhoest, N.E.C. A continuous rainfall model based on vine copulas. 
https://doi.org/10.5194/esurf-2022-1

Preprint. Discussion started: 1 February 2022

(c) Author(s) 2022. CC BY 4.0 License.

Wang, W., Flanagan, D.C., Yin, S. and Yu, B. Assessment of CLIGEN precipitation and storm pattern generation in China. Catena 69, 96-106, 2018.

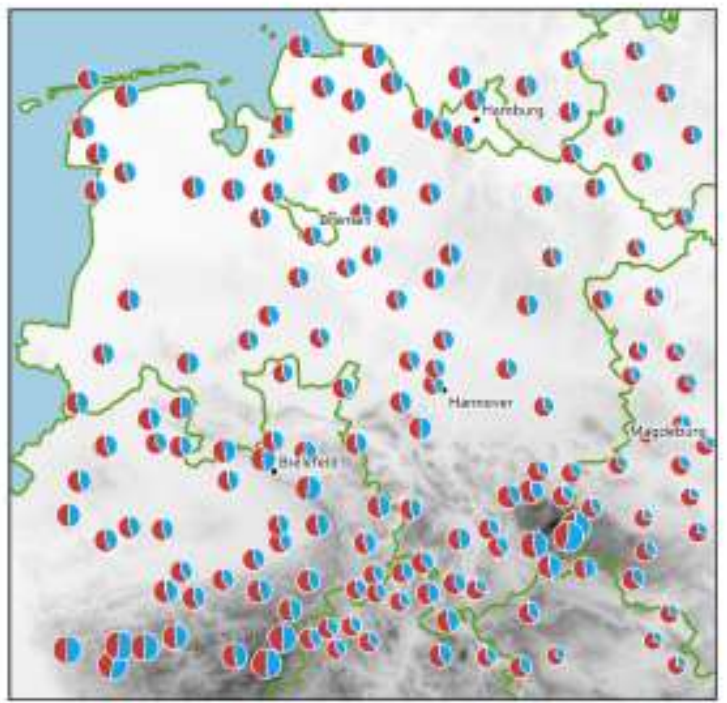

$$
\begin{aligned}
& \text { Stations } \\
& \text { Winter \% } \\
& \text { Summer \% } \\
& 1000 \mathrm{~mm} / \text { year } \\
& 500 \mathrm{~mm} / \text { year } \\
& \text { Elevation } \\
& 1,000 \text { m.a.s.I } \\
& 0 \text { m.a.s.l } \\
& \square \quad \text { Federal States }
\end{aligned}
$$

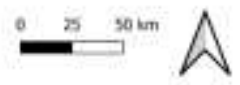

Figure 1: Location of all recording stations ( $N=159)$. Pie charts indicate relative annual volume (radius) and percentage split between summer (red) and winter (blue) precipitation.

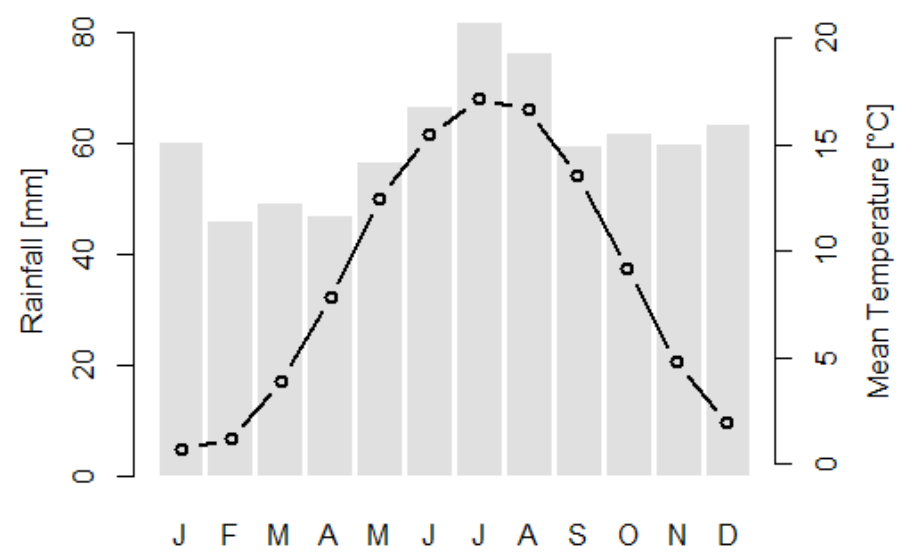

445 Figure 2: Long-term climate (1881-2019) averaged across the German federal state of Lower Saxony that is investigated in the scope of this study. Source: German Weather Service (DWD) Climate Data Center (CDC) (CDC, 2020). 
https://doi.org/10.5194/esurf-2022-1

Preprint. Discussion started: 1 February 2022

(c) Author(s) 2022. CC BY 4.0 License.

\section{Direct-R}

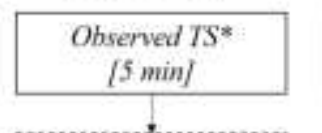

Estimation of $\mathrm{R}$
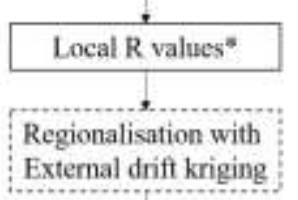

External drift kriging
Direct-P

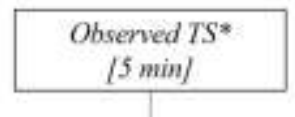

Regionalisation with

Nearest Neighbour

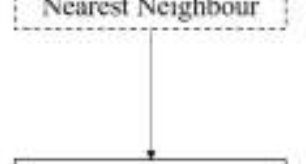

Regionalized TS

[5 $\mathrm{min}$ ]

Estimation of $\mathrm{R}$
ARM
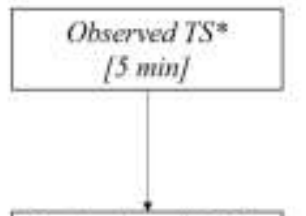

Estimation of ARM model parameters*

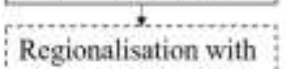

Nearest Neighbour
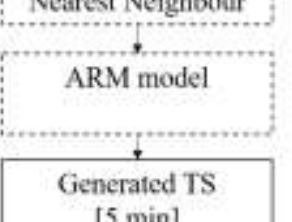

[5 min]

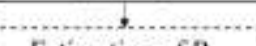

Estimation of $\mathrm{R}$
Disagg
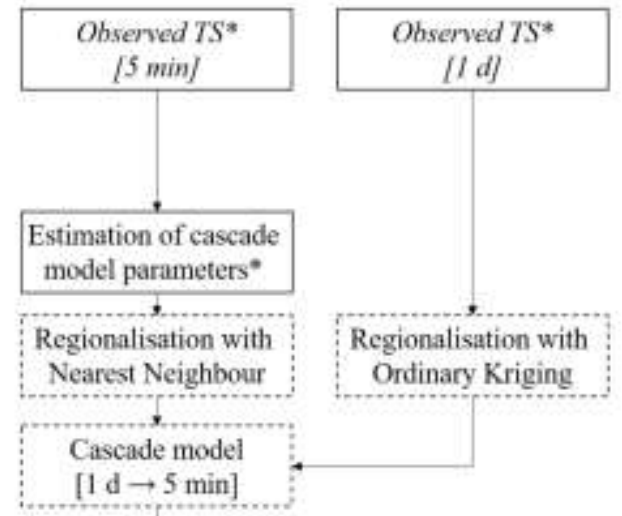

Figure 3: Overview of the estimation of the annual rainfall erosivity (R) including all applied methods (dashed boxes) and data sets (solid boxes, italic written represent input data sets) ['TS' are rainfall time series; '*' indicates data sets affected by the station density scenarios].

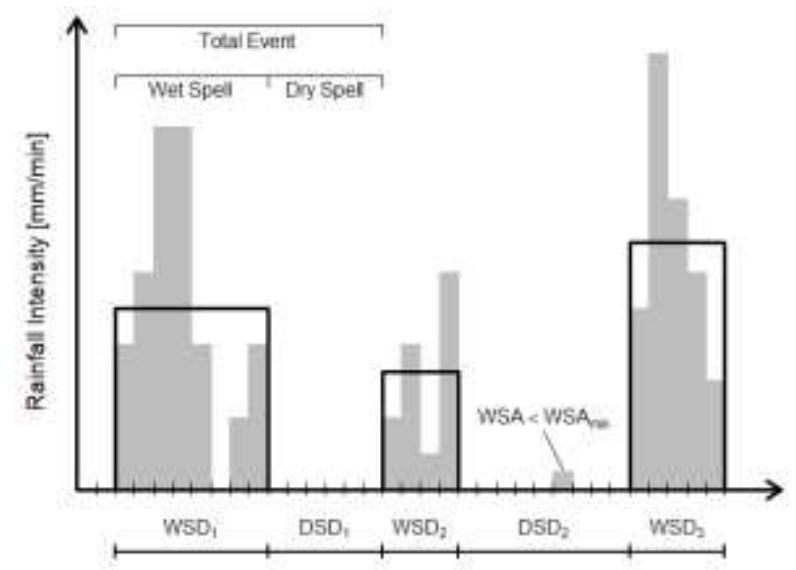

Figure 4: Schematic of the external structure of the ARM model. The black boxes describe rainfall events derived from observations. 
https://doi.org/10.5194/esurf-2022-1

Preprint. Discussion started: 1 February 2022

(c) Author(s) 2022. CC BY 4.0 License.

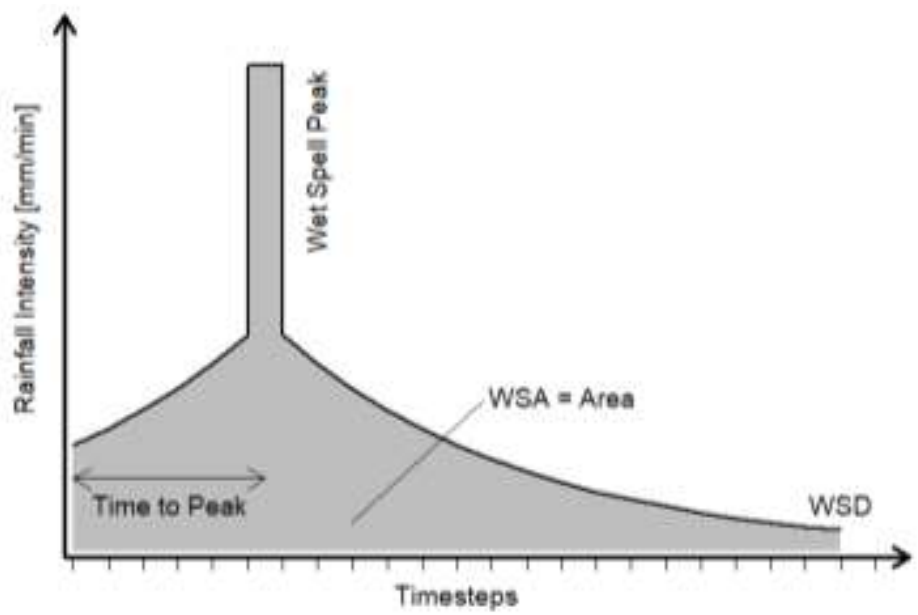

Figure 5: Internal structure of ARM model according to the Callau and Haberlandt (2017).

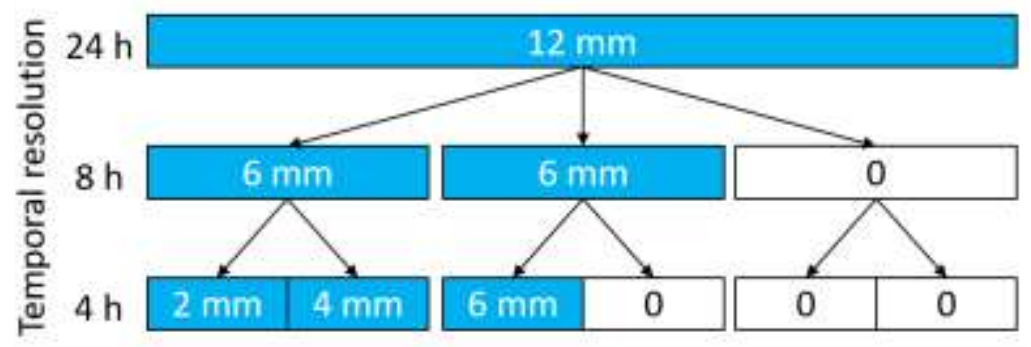

460 Figure 6: General scheme of the cascade model for the first two disaggregation steps with exemplary rainfall amounts for a daily total of $12 \mathrm{~mm}$ (blue boxes = wet time steps). 
https://doi.org/10.5194/esurf-2022-1

Preprint. Discussion started: 1 February 2022

(c) Author(s) 2022. CC BY 4.0 License.

(c) (i)
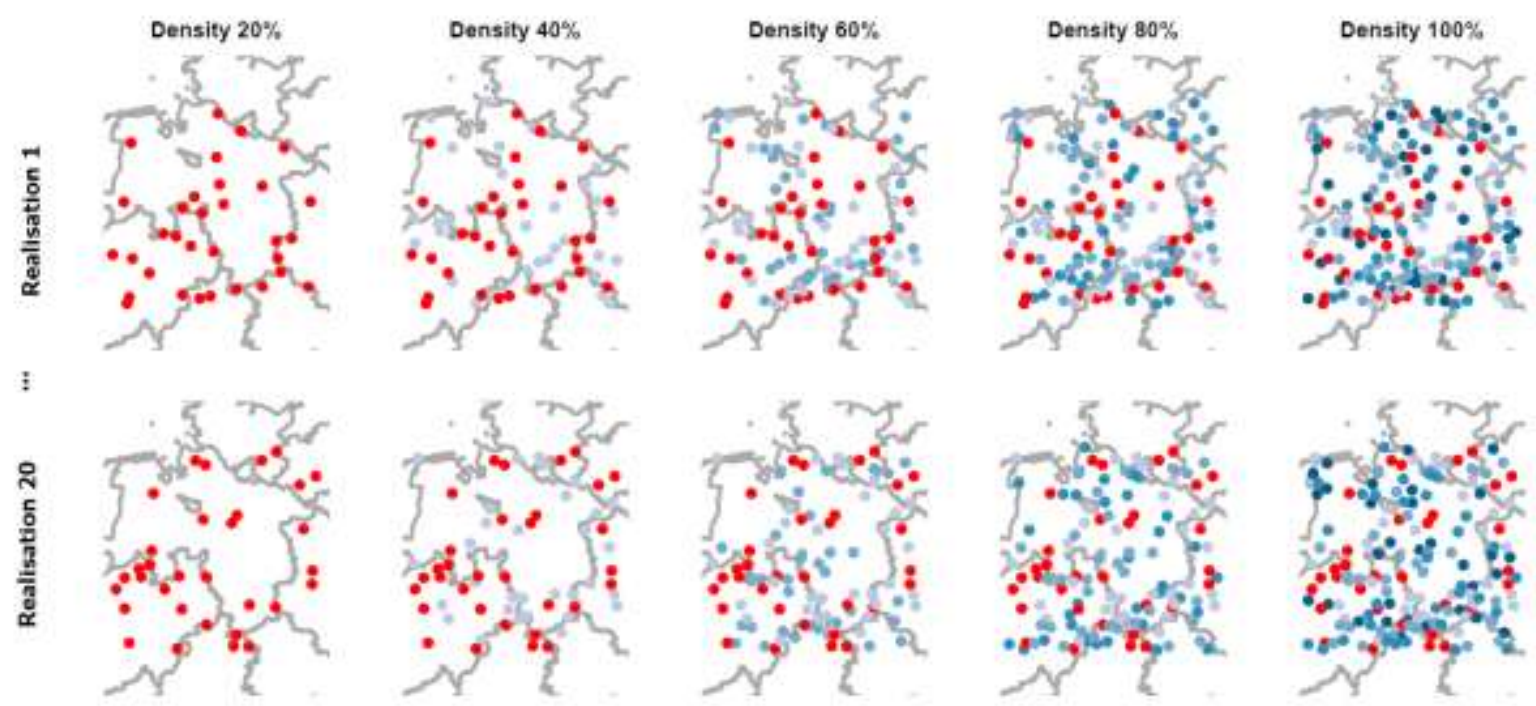

Figure 7: Five different station density scenarios shown for two realisations. The red stations are used for the cross validation for all station densities. The additional stations (blue) provide supplementary information for the regionalisation. 
Mean Annual R

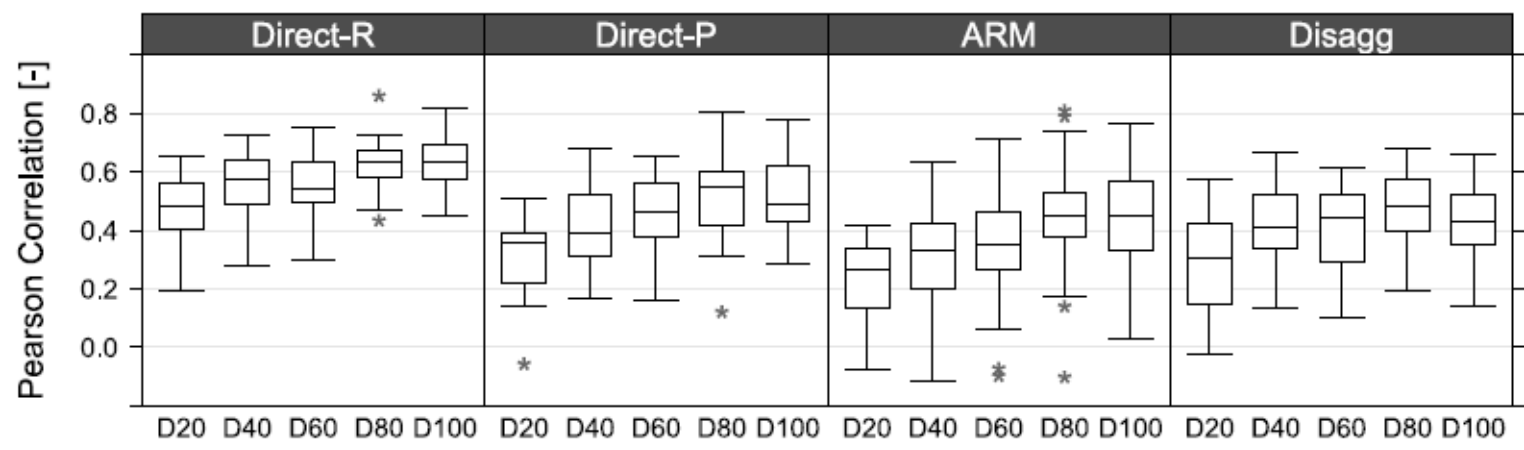

Mean Annual R

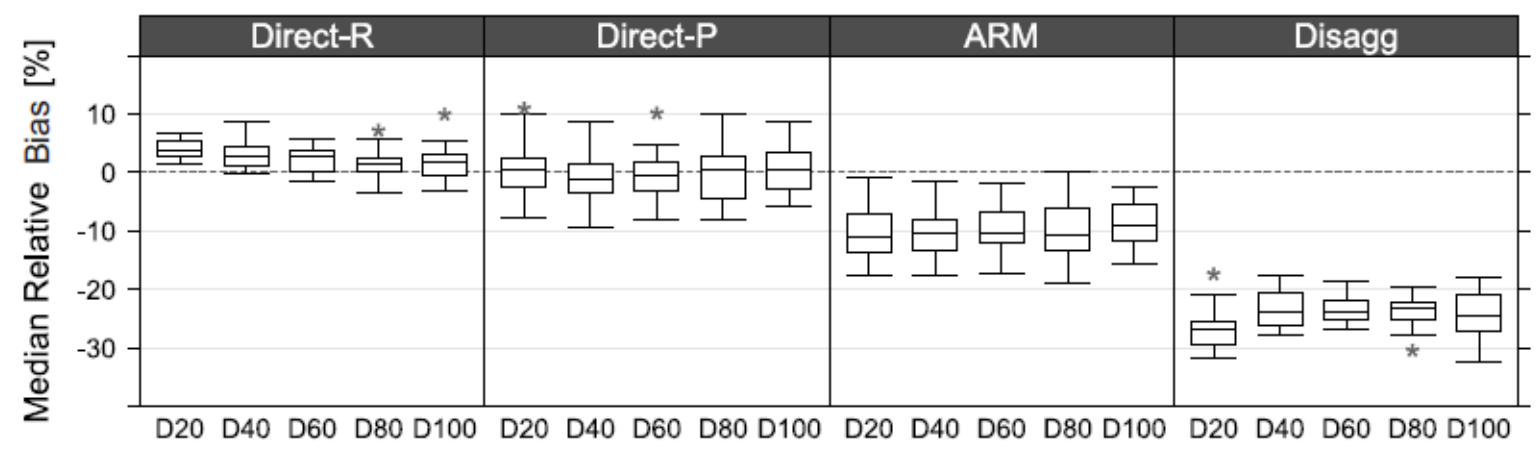

Mean Annual R

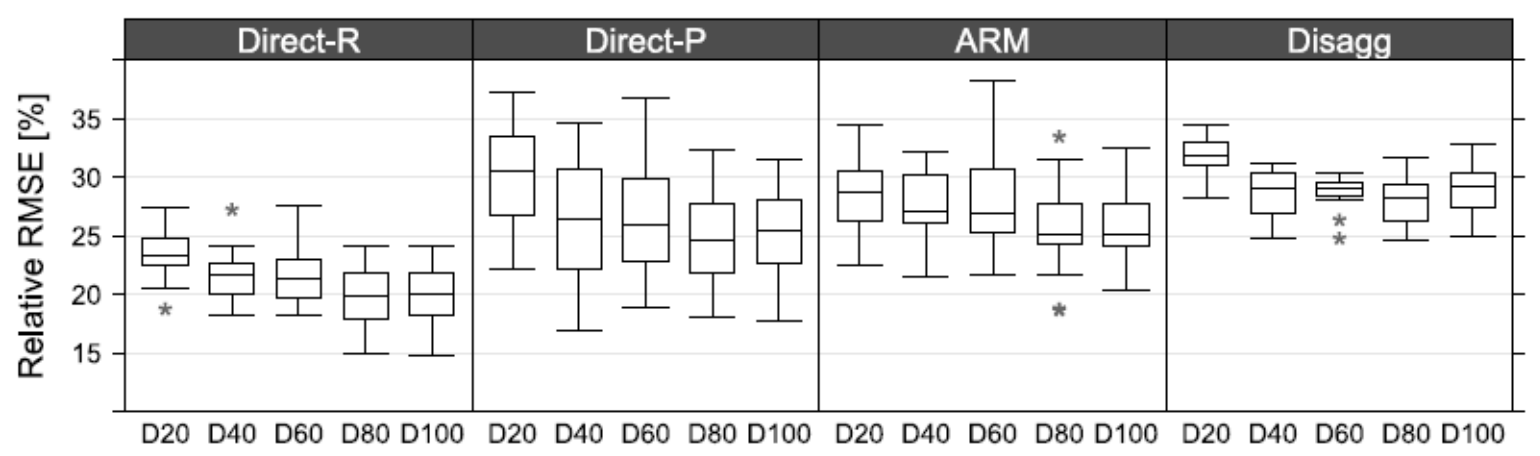

Figure 8: Pearson's Correlation Coefficient, Relative Bias and Relative RMSE results for the four tested methods. Box plots show 


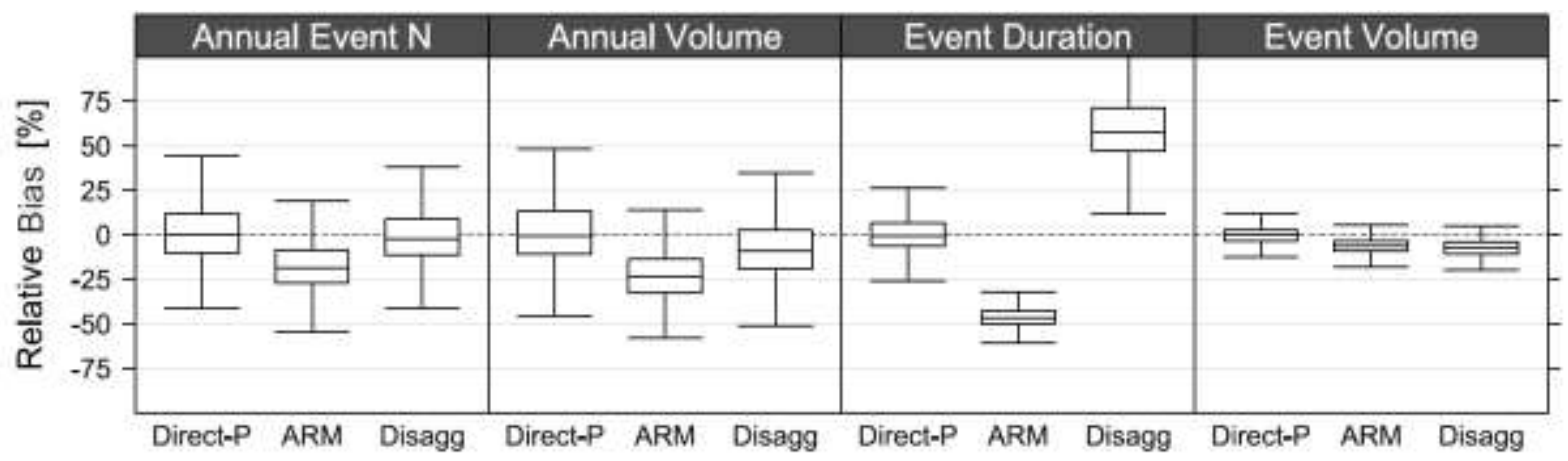

Figure 9: Relative bias of all stations $(\mathrm{N}=32)$ for all realisations $(\mathrm{N}=20)$ and density scenarios $(\mathrm{N}=5)$ for different erosive event variables (for each box plot, $\mathrm{N}=\mathbf{3 2 0 0}$ ). Annual number of erosive events, annual number of all erosive events volume, erosive event duration and erosive event volume are shown. Outliers are excluded for clarity.
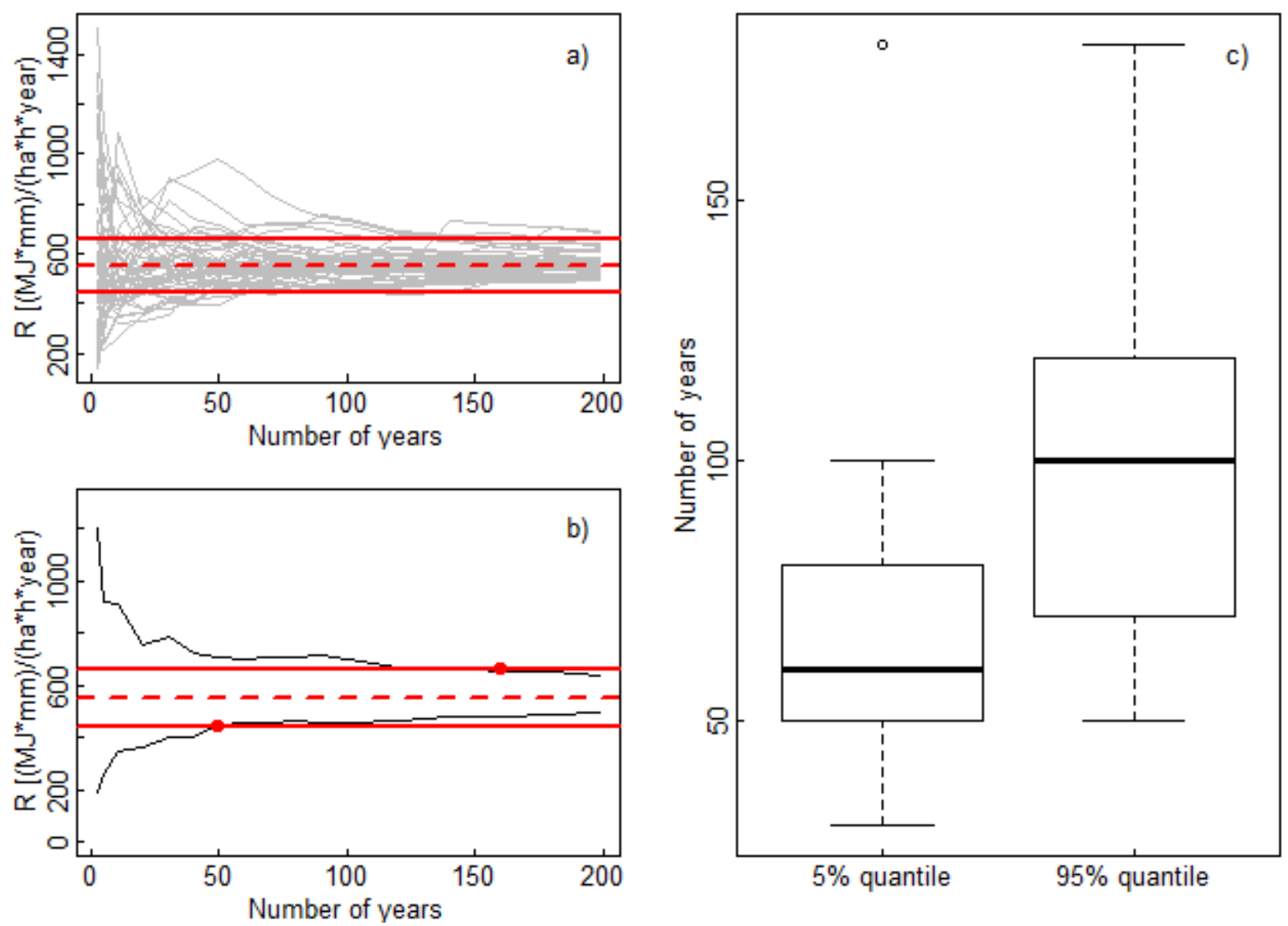

Figure 10: Relationship between mean annual rainfall erosivity and number of years used in the rainfall erosivity calculation. a) shows 50 different realizations (grey lines) together with mean annual value that is calculated using all 50 realisations with 200 years of data (solid red line) and +-20\% of this mean value (dotted red line). b) shows $5 \%$ and $95 \%$ quantile values (black line) calculated based on 50 realizations shown in a) and intersections between these quantile values and +-20\% interval. c) shows boxplots of intersection points for 17 stations for the $5 \%$ and $95 \%$ quantile. a) and b) are shown for station ID $=10113$. 
https://doi.org/10.5194/esurf-2022-1

Preprint. Discussion started: 1 February 2022

(c) Author(s) 2022. CC BY 4.0 License.

Table 1: Median values over all reference stations $(\mathrm{N}=32)$ and realisations $(\mathrm{N}=20)$. Simulated values are given for the $100 \%$ density scenario.

\begin{tabular}{|c|c|c|c|c|c|}
\hline & $\begin{array}{c}\text { Annual } \\
\text { Erosive } \\
\text { Events } \\
{[-]}\end{array}$ & $\begin{array}{c}\text { Annual Erosivity R } \\
{\left[\text { MJ.mm.ha }{ }^{-1} \cdot \mathrm{h}^{-1}\right]}\end{array}$ & $\begin{array}{c}\text { Annual Erosive } \\
\text { Rainfall Volume } \\
{[\mathrm{mm}]}\end{array}$ & $\begin{array}{c}\text { Mean Event } \\
\text { Duration } \\
{[\mathrm{hrs}]}\end{array}$ & $\begin{array}{c}\text { Mean Event } \\
\text { Volume } \\
{[\mathrm{mm}]}\end{array}$ \\
\hline Observed & 14.5 & 642.7 & 303.2 & 22.5 & 21.1 \\
\hline Direct-R & - & 653.8 & - & - & - \\
\hline Direct-P & 14.6 & 647.7 & 303.6 & 22.6 & 21.0 \\
\hline ARM & 11.6 & 580.4 & 227.1 & 12.0 & 16.8 \\
\hline Disagg & 14.2 & 475.5 & 277.8 & 35.9 & 19.6 \\
\hline
\end{tabular}

